2017-03-06

The Effect of Age on Engagement in Preschoolers' Child-Robot Interactions

\author{
Baxter, $\mathrm{P}$
}

http://hdl.handle.net/10026.1/13086

$10.1145 / 3029798.3038391$

All content in PEARL is protected by copyright law. Author manuscripts are made available in accordance with publisher policies. Please cite only the published version using the details provided on the item record or document. In the absence of an open licence (e.g. Creative Commons), permissions for further reuse of content should be sought from the publisher or author. 


\title{
The Effect of Age on Engagement in Preschoolers' Child-Robot Interactions
}

\author{
Peta Baxter ${ }^{1}$, Chiara de Jong ${ }^{1}$, Rian Aarts ${ }^{2}$, Mirjam de Haas ${ }^{1}$, Paul Vogt ${ }^{1}$ \\ ${ }^{1}$ Tilburg center for Cognition and Communication, ${ }^{2}$ Department of Culture Studies, Tilburg School of Humanities \\ Tilburg University \\ Tilburg, The Netherlands \\ p.a.baxter@tilburguniversity.edu, p.a.vogt@tilburguniversity.edu
}

\begin{abstract}
In this study, we investigate the effect of age on preschoolers' engagement - as measured by gaze direction - during a first-time interaction with a social robot. The results revealed significant differences in gaze patterns. Specifically, younger children were more easily distracted, and looked at the robot for a shorter duration and briefer periods of gaze. Moreover, they showed a higher level of reliance on the experimenters. The results have implications for the design of young preschoolers child-robot interactions and specifically for the ways in which the first introductory interactions should occur.
\end{abstract}

\section{Keywords}

Child-robot interaction; engagement; social robots; gaze

\section{INTRODUCTION}

In recent years, there has been an increasing effort to develop and integrate robots as peer-tutors in (pre)schools, for example for the purpose of teaching foreign languages [1]. While most studies have focused on school-aged children, current research is also targeting preschool children, who have high learning flexibility [2]. However, preschool-aged children (2 to 4 years old) undergo major cognitive, emotional and social developments, such as expanding their social competence [3, 4], which must be accounted for in such studies. Whereas older children may have little difficulty engaging in an interaction with a robot, younger children may be more reliant on their caregivers or show less engagement in the interaction, as they are less socially competent. Children between the ages of 3 and 4 show substantial differences in emotional competence, which predicts later social competence [4]. Therefore, we expect that child-robot interactions at those ages will also present some age-related variation. Clarifying these potential age differences is essential as, in order to be efficient, interactive scenarios with robots must be tailored to the diverging needs of children. In the current study, we sought to determine whether there are age-related differences in first-time interactions with a peer-tutor robot of children who have just turned 3 and children who are almost 4 years old. Specifically, we hypothesized that younger children may experience more difficulty engaging with a robot and may rely more heavily on adults if it is their first one-on-one interaction with a robot.

Permission to make digital or hard copies of part or all of this work for personal or classroom use is granted without fee provided that copies are not made or distributed for profit or commercial advantage and that copies bear this notice and the full citation on the first page. Copyrights for third-party components of this work must be honored. For all other uses, contact the Owner/Author(s).

Copyright is held by the owner/author(s).

HRI'17 Companion, March 6-9, 2017, Vienna, Austria.

ACM ISBN 978-1-4503-4885-0/17/03

DOI: http://dx.doi.org/10.1145/3029798.3038391
Since previous research has shown that gaze behavior is a good indicator of engagement, especially in human-agent interaction [5], we measured preschoolers' engagement by means of their gaze direction.

\section{METHODS}

Thirty-two children recruited at preschools in the Netherlands participated in this study (18 female, $M=41.47$ months, $S D=$ 4.74) of which 17 were in the young age group $(M=37.35, S D=$ 2.06) and 15 were in the old age group $(M=46.13, S D=0.99)$. Prior to a one-on-one interaction with the NAO robot, the children took part in a group introduction to familiarize them with the robot. Two experimenters were present during the one-on-one interaction. They kept in the background, only intervening when children required it. The full interaction was filmed, and consisted of an introductory phase followed by a short tutoring session for English as a second language revolving around counting blocks. For this study, we only considered the introductory phase, since we were interested in the initial response to the robot. During this phase $(M$ duration $=5.9$ minutes, $S D=1.09)$ the robot introduced itself and initiated a conversation that encouraged an exchange of personal information. Additionally, a few simple counting tasks revolving around the blocks and the robot's body parts were included. Children were filmed from two viewpoints to account for erratic movements. Gaze behavior (frequency and duration) was analyzed by manually coding the children's gaze towards the robot, the experimenter(s), the blocks, themselves and elsewhere $($ Cohen's Kappa $=.82)$. Glances, i.e. gaze shorter than 1 second, were not considered to be an actual gaze pattern and were therefore added to the nearest annotation.

\section{RESULTS}

To explore the differences in gaze behaviors within each group, we conducted Greenhouse-Geisser corrected repeated-measures ANOVAs (see Figure 1 and 2 for visual representations).

For the younger children, this revealed significant differences in gaze frequency and proportion of time in a certain gaze direction, respectively $F(2.49,39.82)=39.89, p<.001$ and $F(2.06,30.47)=$ $84.79, p<.001$. Specifically, younger children looked at the experimenters more frequently and for a longer proportion of time than elsewhere (respectively, $p=.007 ; p=.012$ ), themselves (respectively, $p=.001 ; p=.001$ ) and more frequently at the blocks $(p=.007)$. Overall though, younger children also looked at the robot more frequently and for a longer proportion of time than at the experimenters $(p<.01)$, the blocks, elsewhere, or themselves, all $p<.001$. For the older children, we found significant differences with regard to gaze frequency and proportion of time in a certain gaze direction, respectively $F(2.35$, $32.84)=21.77, p<.001$ and $F(1.37,19.20)=109.43, p<.001$. Specifically, they looked at the experimenters more frequently than elsewhere $(p=.038)$ and at the blocks for a longer proportion 
of time than elsewhere $(p=.026)$. Just like the younger children, they looked at the robot more frequently and for a longer proportion of time than the experimenters $(p<.01)$, the blocks, elsewhere, or themselves, all $p<.001$.

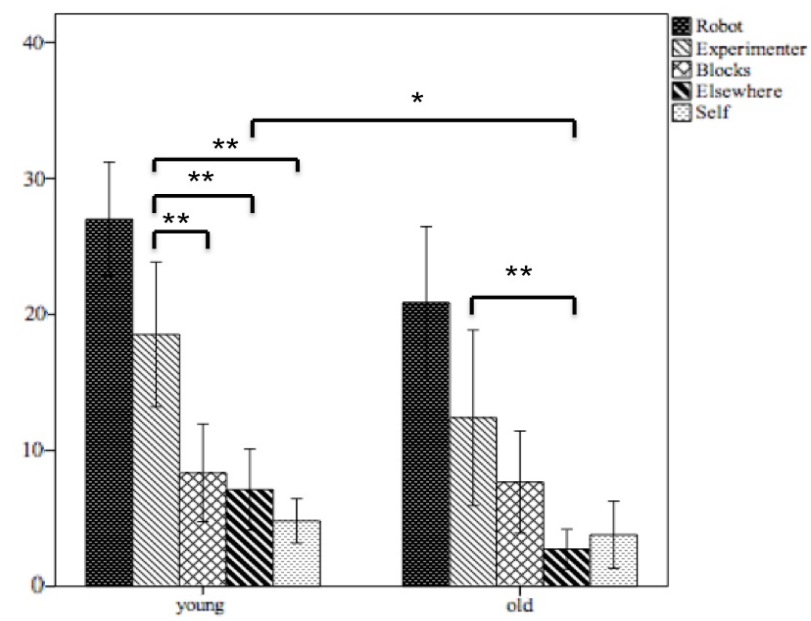

Figure 1. Mean number of occurrences for each gaze direction Note. ${ }^{*} p<.05, * * p<.01$. Robot gaze differed significantly from all other gaze directions, $p<.01$

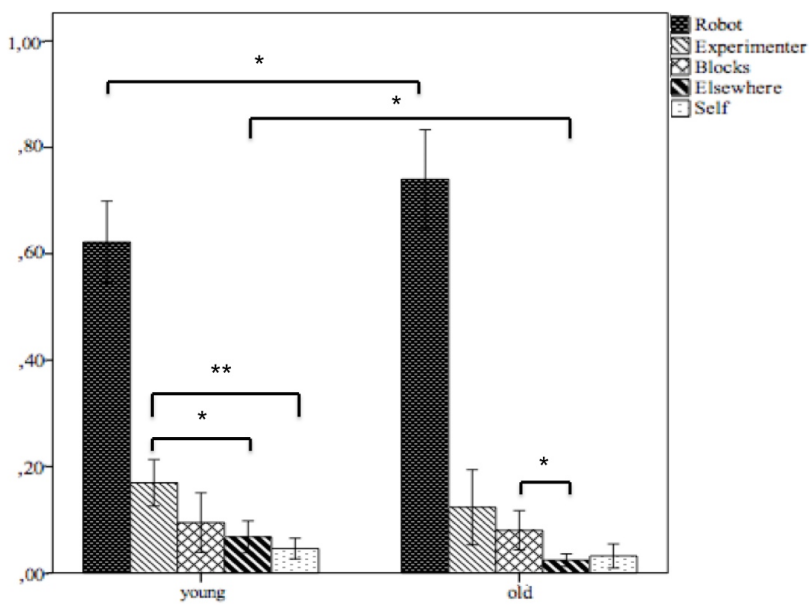

Figure 2. Proportion of time spent on each gaze direction

Note. ${ }^{*} p<.05, * * p<.01$. Robot gaze differed significantly from all other gaze directions, $p<.01$

To analyze the effect of age, t-tests were conducted, both for gaze frequency and proportion of time. Older children looked at the robot for a larger proportion of time $(M=.74, S D=.17)$ than younger children $(M=.62, S D=.15), t(30)=-2.11, p=.043$. The average time (in seconds) per gaze on the robot was higher for older children $(M=14.97, S D=8.60)$ than for younger children $(M=9.74, S D=5.73), t(30)=-2.05, p=.049$. Additionally, younger children looked elsewhere for a larger proportion of time $(M=.07, S D=.06)$ and more frequently $(M=7.12, S D=5.81)$ than older children (respectively $M=.02, S D=.02, M=2.73, S D$ $=2.66)$, respectively $t(30)=2.74, p=.010$ and $t(30)=2.68, p=$ .012 .

\section{DISCUSSION AND CONCLUSION}

The current study sought to determine the effect of age on preschoolers' engagement during first time one-on-one child- robot interactions. The results indicate that, between the ages of 3 and 4, age differences as small as 10 months lead to diverging engagement behaviors towards a robot. In our experiment, both younger and older children looked at the robot more often and for a longer proportion of time than anywhere else, illustrating the overall interest in the robot. However, younger children spent less time - overall as well as per gaze - looking at the robot than older children. They also looked elsewhere more often and for a longer proportion of time. This suggests that while younger children do show interest in the robot and are engaged with it, they might be less able to sustain direct attention towards it than older children.

We postulate that these results are caused by the fact that younger children are more easily distracted by their surrounding and have more trouble focusing on a task for an extended period of time, unlike the older children, who were mainly focused on the robot. In addition, given that younger children looked at the experimenters more often and for a larger proportion of time than anywhere else (other than the robot), we hypothesize that they need additional support, reassurance and feedback in their first interaction with a robot. For instance, it was relatively common for the younger children to look at the experimenters after they had answered one of the robot's questions. Further analyses of the experimenters' interventions and children's requests for help should contribute to verifying this hypothesis. The results of the current study have implications for the design of (first-time) interactions between preschoolers and social robots, with special attention required to providing suitable support for the youngest children.

\section{ACKNOWLEDGMENTS}

This work has been supported by the EU H2020 L2TOR project (grant 688014). The authors would like to thank the research trainee program of the Tilburg School of Humanities for their support. We also thank Kinderopvanggroep Tilburg and all preschools for participating in this research.

\section{REFERENCES}

[1] Kanda, T., Hirano, T., Eaton, D., and Ishiguro, H. 2004. Interactive robots as social partners and peer tutors for children: A field trial. Hum.-Comput Interact., 19, 61-84.

[2] Belpaeme, T., Kennedy, J., Baxter, P., Vogt, P., Krahmer, E. E., Kopp, S., ... and Pandey, A. K. 2011. L2TOR-Second Language Tutoring using Social Robots. In Proceedings of the 1st Int. Workshop on Educ. Robots. Springer

[3] Denham, S. A., and Couchoud, E. A. 1990. Young preschoolers' understanding of emotions. Child Study J., 20, 171-192.

[4] Denham, S. A., Blair, K. A., DeMulder, E., Levitas, J., Sawyer, K., Auerbach-Major, S., and Queenan, P. 2003. Preschool emotional competence: Pathway to social competence?. Child Dev., 74, 238-256.

[5] Nakano, Y. I., \& Ishii, R. 2010. Estimating user's engagement from eye-gaze behaviors in human-agent conversations. In Proceedings of the 15th Int. conference on Intelligent User Interfaces (Hong-Kong, China, February 07 - 10, 2010). ACM, New York, NY, 139-148. 